\title{
Children Consuming Cassava as a Staple Food are at Risk for Inadequate Zinc, Iron, and Vitamin A Intake
}

\author{
Alison Gegios • Rachel Amthor • Busie Maziya-Dixon • \\ Chedozie Egesi $\cdot$ Sally Mallowa $\cdot$ Rhoda Nungo $\cdot$ \\ Simon Gichuki • Ada Mbanaso • Mark J. Manary
}

Published online: 18 February 2010

(C) The Author(s) 2010. This article is published with open access at Springerlink.com

\begin{abstract}
Cassava contains little zinc, iron, and $\beta$-carotene, yet it is the primary staple crop of over 250 million Africans. This study used a 24-hour dietary recall to test the hypothesis that among healthy children aged $2-5$ years in Nigeria and Kenya, cassava's contribution to the childrens' daily diets is inversely related to intakes of zinc, iron, and vitamin A. Dietary and demographic data and anthropometric measurements were collected from 449 Kenyan and 793 Nigerian children. Among Kenyan children $89 \%$ derived at least $25 \%$ of their dietary energy from cassava, while among the Nigerian children $31 \%$ derived at least $25 \%$ of energy from cassava. Spearman's correlation coefficient between the fraction of dietary energy obtained from cassava and vitamin A intake was $r=-0.15, P<0.0001$, zinc intake was $r=-0.11$, $P<0.0001$ and iron intake was $r=-0.36, P<0.0001$. In Kenya, $59 \%$ of children consumed adequate vitamin A, $22 \%$ iron, and $31 \%$ zinc. In Nigeria, $17 \%$ of children had adequate intake of vitamin A, $57 \%$ iron, and $41 \%$ zinc.
\end{abstract}

\footnotetext{
A. Gegios $\cdot$ R. Amthor • M. J. Manary $(\bowtie)$

Department of Pediatrics, St. Louis Children's Hospital,

Washington University School of Medicine,

One Children's Place,

St. Louis, MO 63110, USA

e-mail: manary@kids.wustl.edu

B. Maziya-Dixon

International Institute of Tropical Agriculture,

Ibadan, Nigeria

C. Egesi $\cdot$ A. Mbanaso

National Root Crops Research Institute,

Umudike, Abia State, Nigeria

S. Mallowa $\cdot$ R. Nungo $\cdot$ S. Gichuki

Kenya Agricultural Research Institute,

Kakamega,

Nairobi, Kenya

Consumption of cassava is a risk factor for inadequate vitamin $\mathrm{A}$, zinc and/or iron intake.

Keywords Cassava $\cdot$ Iron · Micronutrient deficiency . Vitamin A - Zinc

\begin{abstract}
Abbreviations
UNICEF The United Nations Children's Fund

WHO World Health Organization
\end{abstract}

\section{Introduction}

Micronutrient deficiencies afflict millions of children in sub-Saharan Africa, increasing their susceptibility to common infections and limiting their cognitive and physical development. Vitamin A and zinc deficiencies are estimated to cause 600,000 and 400,000 deaths annually, respectively [1]. These deficiencies account for $9 \%$ of global childhood disability adjusted life years, a measure which economists and policy makers use to assess health impact [1]. Subclinical vitamin A deficiency renders 250,000-500,000 children blind annually, while zinc deficiency increases the risk of death from diarrhea, malaria, and respiratory disease [2]. Iron deficiency is the most common nutritional problem worldwide, and contributes to maternal deaths in pregnancy and parturition [1]. The principle manifestation of iron deficiency is anemia; iron deficiency also compromises the immune system and is associated with limited cognitive development in children. Among pre-school aged children worldwide, $23 \%$ suffer from iron deficiency anemia [1].

In the developing world, vitamin A is usually consumed in the form of $\beta$-carotene, which is present in orange and dark green leafy vegetables such as sweet potatoes, squash, 
orange fruits, and plant leaves. Availability of such foods is often seasonal and their consumption is sporadic in foodinsecure environments. The primary sources of zinc in the diets of the poor are whole-grain cereals and legumes. These foods have a high concentration of phytates, which form insoluble complexes with zinc and, consequently, reduce its bioavailability [3]. As a result, typical diets often do not provide adequate zinc. Iron is primarily obtained from legumes in the developing world, but the quantity and bioavailability of iron in these sources is often insufficient to prevent iron deficiency [4].

Cassava is the staple food of 250 million of the poorest Africans [5]. Cassava has a relatively high tolerance to drought. The cyanide-rich peel of the cassava tuber protects it from boring pests. Once cassava matures as a crop, it remains viable and edible in the ground for up to 3 years. These characteristics make cassava a preferred crop to afford food security to vulnerable subsistence farming communities in Africa [6,7]. While cassava is an excellent energy source, it contains $<1 \mu \mathrm{g} / 100 \mathrm{~g} \beta$-carotene, $\approx 3 \mu \mathrm{g} /$ $100 \mathrm{~g}$ zinc, and $\approx 4 \mu \mathrm{g} / 100 \mathrm{~g}$ iron [8].

Children whose diets consist largely of cassava may be vulnerable to micronutrient deficiencies. This study tested the hypothesis that among children in Nigeria and Kenya who consume cassava as a staple food, the fraction of cassava consumption is inversely correlated with dietary intake of zinc, iron, and vitamin A. Dietary and cost data were used to estimate the cost of a diet with an adequate micronutrient intake, as well as the cost savings if cassava was biofortified with $\beta$-carotene, iron or zinc.

\section{Methods}

\section{Subjects}

Subjects were healthy children aged 2-5 years living in southeast Nigeria and around Lake Victoria in Kenya, areas where cassava is consumed as a staple food. In Kenya, 449 healthy children were recruited for this study during April 2009. Children were excluded from participation if they had a chronic illness or disability, were breastfeeding, or were not permanent residents of the study area. If more than one child in a family was eligible, the younger was chosen to participate. This study was approved by the Human Research Protection Office of Washington University and by the National Ethics Review Committee of the Kenya Medical Research Institute.

Data collected in 2001-2003 for the purposes of assessing the national nutritional status of Nigeria were used for this study [9]. Each state in Nigeria was assigned to one of three agro-ecological zones; all 793 children surveyed who lived in the humid-forest zone, the area where cassava consump- tion is greatest, were included in this study. All children from the other two agro-ecological zones were excluded because $<1 \%$ of these children consumed $>25 \%$ of daily energy as cassava. A child-mother pair was chosen from each randomly sampled house. If more than one child in a household was eligible, the youngest child was selected. Ethical clearance was granted to the survey from the Federal Ministry of Health through the Nutrition Division of the Ministry.

\section{Study Design}

Purposive sampling of Kenyan and Nigerian individuals was used. Furthermore, children aged 2-5 years were chosen as the study population because they are no longer breast feeding, quantification of macronutrient intake by survey methods has been shown to be accurate, and they are a vulnerable group for whom dietary diversity is limited. In Kenya, children were recruited from 15 villages in Kuria, Teso and Samia districts. From each village, a random sample of 30 children was chosen. A sample size of 450 was determined using estimates of iron intake data to achieve a precision of $10 \%$. Considering each of the three districts to be independent and unrelated, a sample size of 144 per district was calculated.

In Nigeria, the states were selected based on their high reliance on cassava. The survey method has been described previously $[9,10]$. Within each state, a listing of all local government areas was obtained and these areas were then separated by degree of urbanization (rural, medium, and urban) [11]. The survey areas were selected with the goals of ensuring a range of rural/urban conditions. Local government areas were then divided into smaller demographic units. Three of these smaller demographic units were randomly selected for the survey. For each of these small units, 30 households were randomly chosen, for a total of 793 children recruited.

The primary outcomes of this study were the Spearman's correlation coefficients relating the fraction of dietary energy obtained from cassava and zinc, iron and vitamin A intake.

\section{Dietary Recall}

In Kenya, a 24-hour recall method was used to estimate dietary intake $[12,13]$. Two days before the food recall, caregivers were asked to observe the quantities and types of food that their children consumed on a designated day. Each caregiver was given a graduated cup to help standardize quantities when cooking and feeding on that day. Caregivers were also asked to note any food or meals given to the child outside of the home or any special circumstances (e.g. visitors in the home, special celebration). Approximately $10 \%$ of children were surveyed twice using the same method to determine the variation in 
micronutrient intake for the population. Caregivers also answered a questionnaire providing basic demographic and household information. Each child's weight was measured to the nearest $10 \mathrm{~g}$ and height was measured in triplicate to the nearest $\mathrm{mm}$.

In Nigeria, a similar 24-hour recall method was used to estimate dietary intake [13]. Interviewers were provided with a food instruction booklet to collect descriptions of the foods consumed by respondents and their respective amounts. Each reported food description was compared to relevant food probes in the food instruction booklet. The respondents used measurement guides to approximate the amount of food eaten. Measurements consisted of: food models, prices, volumes, and sizes. The questionnaire also included information about household composition, socioeconomic status of the household, trends in food availability/frequency of food consumption, and household food expenditures. All interviews were conducted in person with the child's caregiver, usually his/her mother. Samples of Nigerian food prepared and eaten by household members were sent for compositional analysis whenever possible [9].

\section{Data Analysis}

Each subject was assigned a study number unlinked to identifiers. Data were entered in a Microsoft Excel spreadsheet. Vitamin A, zinc and iron intake for each Kenyan subject was calculated using two East African food composition tables [14, 15]. For the Nigerian subjects, original data collection sheets were not available, but instead an aggregate spreadsheet without identifiers was the primary data source.

Adequate zinc, iron and vitamin A intake were assumed to be the Dietary Reference Intakes determined by the Institute of Medicine [16]. Anthropometric indices were calculated using the WHO 2005 growth standards [17]. Spearman's correlation coefficients were determined for fraction of energy consumed obtained from cassava and zinc, iron, and vitamin A intake (SPSS 17.0, Chicago, IL, USA). A non-parametric measure of correlation was chosen because the nutrient intake data are unlikely to be normally distributed. A $P<0.05$ was considered statistically significant.

Dietary diversity was scored by three methods. First, all foods were categorized into one of 12 general types, such as cereals, fish, sugar, and fats, and children were given a 12 point score [18]. The second method defined whether animal-source foods were consumed on the survey day, and the final method used a numerical count of the number of different foods eaten on the survey day [19].

\section{Cost Analysis of Diets and Impact of Biofortification}

Market surveys of all food prices per unit weight were conducted in Busia, Kenya and Umudike, Nigeria, repre- sentative small towns in the cassava consuming areas in proximity to where the dietary recalls were conducted. For the foods that are exclusively grown and then consumed by farm families without passing through a market, a cost of production was assigned. These foods included cassava, millet and sorghum; their prices were much lower than the market prices of other staple foods. Excel spreadsheets of all foods, nutrient contents, and prices were prepared. Solver, a linear programming tool in Excel, was used to estimate the minimum cost of providing a diet with adequate amounts of vitamin A, zinc, and iron for 2-5 year old children [20], assuming that these children could not consume more than twice as much of any broad category of food as they did habitually in the 24-hour dietary recall surveys.

Additionally, to estimate the impact that biofortified cassava would have on micronutrient intake in this population, the micronutrient content of cassava was arbitrarily increased 20 -fold for $\beta$-carotene and 4 -fold for iron and zinc, and the nutrient intake and dietary cost estimates recalculated.

\section{Results}

The survey included 449 Kenyan and 793 Nigerian children aged 2-5 years (Table 1).

Kenyans derived $59 \%$ of their energy from cassava, while $15 \%$ of dietary energy of Nigerian children was derived from cassava (Table 2).

Micronutrient intakes were inadequate in a large fraction of the children (Table 3), and $89 \%$ of Kenyan children and $31 \%$ of Nigerian children obtained $>25 \%$ of their dietary energy from cassava. The dietary diversity score was $4.0 \pm$ 1.4 for Nigerian children and $4.5 \pm 1.3$ for Kenyan children (Table 3).

54 Kenyan children were surveyed twice. On the first survey day vitamin A, zinc and iron intakes were $420 \pm$ $550 \mu \mathrm{g} / \mathrm{d}, 3.4 \pm 4.7 \mathrm{mg} / \mathrm{d}$ and $6.1 \pm 2.5 \mathrm{mg} / \mathrm{d}$, respectively (mean $\pm \mathrm{SD}$ ), and on the second survey day vitamin $\mathrm{A}$, zinc and iron intakes were $450 \pm 420 \mu \mathrm{g} / \mathrm{d}, 3.1 \pm 1.3 \mathrm{mg} / \mathrm{d}$ and $6.6 \pm 2.8 \mathrm{mg} / \mathrm{d}$. The intraindividual SDs, calculated from the second measurement, for vitamin $\mathrm{A}$, zinc and iron were $310 \mu \mathrm{g} / \mathrm{d}, 1.4 \mathrm{mg} / \mathrm{d}$ and $2.0 \mathrm{mg} / \mathrm{d}$, respectively.

The fraction of dietary energy provided by cassava was negatively correlated with vitamin A intake $(r=-0.15, P<$ $0.0001)$, with zinc intake $(r=-0.11, P<0.0001)$ and with iron intake $(r=-0.36, P<0.0001)$.

Considering both populations together, $33 \%$ of children had an adequate intake of vitamin A, $45 \%$ had an adequate intake of iron, and $37 \%$ had an adequate intake of zinc. If the micronutrient content of cassava was to be increased 20 -fold for $\beta$-carotene, and 4 -fold for iron and zinc, the fraction of this population that would have an adequate 
Table 1 Demographic and socioeconomic profile of study populations
Data expressed as $n(\%)$ or mean \pm standard deviation

\begin{tabular}{lcr}
\hline Features & Nigeria $n=793$ & Kenya $n=449$ \\
\hline Sex, male & $322(49 \%)$ & $220(49 \%)$ \\
Age (mo) & $38 \pm 10$ & $40 \pm 10$ \\
Weight-for-height z-score & $0.0 \pm 1.2$ & $-0.2 \pm 0.9$ \\
Height-for-age z-score & $-1.5 \pm 1.8$ & $-1.6 \pm 1.3$ \\
Weight-for-age z-score & $-0.8 \pm 1.3$ & $-1.0 \pm 1.0$ \\
Occupation of head of household & $278(32 \%)$ & $330(75 \%)$ \\
Farming & $136(16 \%)$ & $15(3 \%)$ \\
Trading & $118(14 \%)$ & $5(1 \%)$ \\
Civil servant & $175(20 \%)$ & $1(14 \%)$ \\
Artisan & $11(1 \%)$ & $1(-)$ \\
Fisherman & $149(17 \%)$ & $29(7 \%)$ \\
Other & $452(52 \%)$ & 0 \\
Home is electrified & $298(34 \%)$ & $198(44 \%)$ \\
Uses a source of clean water (city water, borehole) & & \\
\hline
\end{tabular}

vitamin A intake would be $61 \%$, for iron it would be $86 \%$, and for zinc it would be $67 \%$.

Results of the cost analysis in Kenya indicate that adequate dietary $\beta$-carotene can be provided for $\$ 0.22 / \mathrm{d}$, adequate dietary iron for $\$ 0.25 / \mathrm{d}$, adequate dietary zinc for $\$ 0.74 / \mathrm{d}$, and adequate amounts of vitamin $\mathrm{A}$, zinc and iron for $\$ 0.74 /$ d. For a Kenyan child consuming cassava as a staple, if the $\beta$-carotene content is increased 20 -fold, zinc content increased 4-fold and iron content 4-fold, the cost of providing all of these micronutrients and adequate daily macronutrients falls to $\$ 0.16 / \mathrm{d}$.

Results of the cost analysis in Nigeria indicate that adequate dietary $\beta$-carotene can be provided for $\$ 0.59 / \mathrm{d}$, adequate dietary iron for $\$ 0.64 / \mathrm{d}$, adequate dietary zinc for
$\$ 0.59 / \mathrm{d}$ and adequate amounts of vitamin $\mathrm{A}$, iron and zinc for $\$ 0.64 / d$. For a Nigerian child consuming cassava as a staple, if the $\beta$-carotene content is increased 20 -fold, zinc content increased 4-fold and iron content 4-fold, the cost of providing all of these micronutrients and adequate daily macronutrients falls to $\$ 0.53 / \mathrm{d}$.

\section{Discussion}

The rates of inadequate vitamin $\mathrm{A}$, zinc and iron intake were very high in rural 2-5 year old children who consume cassava as a staple food. Cassava consumption was negatively correlated with vitamin $\mathrm{A}$, zinc and iron intake,

Table 2 Sources of energy in the diets of cassava consuming children and typical micronutrient density of the staple foods

\begin{tabular}{|c|c|c|c|c|c|c|}
\hline Food or food group & $\begin{array}{l}\text { Nigeria } \\
n=793\end{array}$ & $\begin{array}{l}\text { Kenya } \\
n=449\end{array}$ & $\begin{array}{l}\text { Representative } \\
\text { food from group }\end{array}$ & $\begin{array}{l}\text { Vitamin A } \\
\text { content } \mu \mathrm{g} / \mathrm{kcal}\end{array}$ & $\begin{array}{l}\text { Zinc content } \\
\mu \mathrm{g} / \mathrm{kcal}\end{array}$ & $\begin{array}{l}\text { Iron content } \\
\mu \mathrm{g} / \mathrm{kcal}\end{array}$ \\
\hline Cassava & $15 \%$ & $59 \%$ & Cassava & 0 & 0.2 & 1.6 \\
\hline Maize & $22 \%$ & $7 \%$ & Maize & 0 & 0.2 & 3.3 \\
\hline Rice & $14 \%$ & $1 \%$ & Rice & 0 & 3.3 & 11.4 \\
\hline Sorghum & $1 \%$ & $10 \%$ & Sorghum & 0.1 & 0.2 & 30 \\
\hline Wheat & $8 \%$ & $1 \%$ & Wheat & 0.2 & 1.8 & 3.2 \\
\hline Animal source foods & $3 \%$ & $7 \%$ & Egg & 1.1 & 6.8 & 7.7 \\
\hline Legumes & $9 \%$ & $3 \%$ & Cowpea & 0 & 9.4 & 22.3 \\
\hline Fruits & $4 \%$ & $3 \%$ & Papaya & 1.4 & 1.8 & 2.7 \\
\hline Green leafy vegetables & $10 \%$ & $4 \%$ & Okra & 2.0 & 4.3 & 15.3 \\
\hline Yams & $11 \%$ & $0 \%$ & Yams & 0 & 0.1 & 6.4 \\
\hline Banana & $2 \%$ & $1 \%$ & Banana & 0.2 & 1.7 & 3.3 \\
\hline Sweet potato & $0 \%$ & $3 \%$ & Sweet potato & 32 & 2.6 & 5.3 \\
\hline
\end{tabular}

Data for Nigeria and Kenya expressed as fraction of daily dietary energy

Representative food chosen on the basis of being most commonly used food in the food group, nutrient composition values taken from Nigerian Food Composition Table [9] 
Table 3 Cassava, vitamin A, zinc and iron intake of children aged $2-5$ years

Values expressed as mean SD for continuous parameters, $n(\%)$ or dichotomous parameters.

DRI, Dietary Reference Intake, is the "lowest continuing intake level of a nutrient that will maintain a defined level of nutriture in an individual". For Vitamin A, DRI $=300 \mu \mathrm{g} / \mathrm{d}$ for 2-4 year old children and $400 \mu \mathrm{g} / \mathrm{d}$ for $4-5$ year old children. For zinc, DRI $=3 \mathrm{mg} / \mathrm{d}$ for 2-4 year old children and $5 \mathrm{mg} / \mathrm{d}$ for 4-5 year old children. For iron, DRI $=7 \mathrm{mg} / \mathrm{d}$ for 2-4 year old children and $10 \mathrm{mg} / \mathrm{d}$ for $4-5$ year old children [17].

\begin{tabular}{lll}
\hline & Nigeria $n=793$ & Kenya $n=449$ \\
\hline Energy intake $(\mathrm{kcal} / \mathrm{kg})$ & $84 \pm 10$ & $76 \pm 8$ \\
Dietary Vitamin A intake $(\mu \mathrm{g} / \mathrm{d})$ & $221 \pm 288$ & $378 \pm 679$ \\
Dietary Zinc intake $(\mathrm{mg} / \mathrm{d})$ & $3.8 \pm 2.9$ & $2.8 \pm 1.5$ \\
Dietary Iron intake $(\mathrm{mg} / \mathrm{d})$ & $11.5 \pm 9.0$ & $5.9 \pm 3.7$ \\
Vitamin A intake $<$ DRI & $656(83 \%)$ & $182(41 \%)$ \\
Zinc intake $<$ DRI & $460(59 \%)$ & $311(69 \%)$ \\
Iron intake $<$ DRI & $340(43 \%)$ & $349(78 \%)$ \\
Fraction Cassava Intake, \% of total dietary energy & & $295(66 \%)$ \\
$>50 \%$ & $80(10 \%)$ & $103(23 \%)$ \\
$25-50 \%$ & $170(21 \%)$ & $17(4 \%)$ \\
$15-25 \%$ & $115(15 \%)$ & $15(3 \%)$ \\
$5-15 \%$ & $208(26 \%)$ & $19(4 \%)$ \\
$<5 \%$ & $220(28 \%)$ & $4.5 \pm 1.3$ \\
Dietary Diversity & & $4.6 \pm 1.2$ \\
Household dietary diversity score $(0-12)$ & $4.0 \pm 1.4$ & $319(71 \%)$ \\
Number of different food items consumed & $7.0 \pm 2.7$ & $271(41 \%)$ \\
Consumed an animal-source food & &
\end{tabular}

identifying cassava consumption as a risk factor for micronutrient deficiency.

A limitation of this study is the uncertainty associated with a single 24-hour recall to determine dietary intake, as dietary intake is known to vary substantially day-to-day $[12,13]$. A series of consecutive recalls is more accurate than a single one for determination of an individual's dietary intake. Repeating the recall in 54 children showed that the populations estimates of micronutrient intake were likely to be accurate within $10 \%$, since mean intake values varied by $10 \%$ or less. It is established, however, that when considering a population, a single dietary recall provides an accurate estimate of the nutrient intake and nutrient deficits of the population as a whole $[13,21]$. The dietary recall method used in this study alerted participants of the survey date in advance. This has been shown to improve the accuracy of the recall, but it also offers participants the opportunity to change their dietary intake in anticipation of the survey. This has been noted to a source of bias in developed world dietary surveys, but is thought to be less of a problem in populations that consume a monotonous diet in the developing world. The study population was predominantly Africans, who, either, grow their own crops, or obtain their food from extended family members who grow crops. Thus, our findings should not be extended to populations with more dietary diversity, such as wage earners or urban dwellers who primarily purchase food. Thirdly, this assessment was restricted to 2-5 year old children and therefore it might not be applicable to other age groups who obtain more of their food prepared outside the home.

Since vitamin A supplements are routinely given to children in the developing world [22], vitamin A intake may be low while vitamin A status may not be. Among the individuals surveyed in Kenya, 33\% reported receiving vitamin A supplements in the 6 months prior to the survey. National coverage figures for Nigeria indicate that $55 \%$ of children receive annual vitamin A supplements [23]. However, our survey was designed to identify children with inadequate vitamin A intake, not poor vitamin A status. It is acknowledged that food is the preferred vehicle to receive micronutrients, and these surveys do accurately report what micronutrients were received from food sources [24].

The diets in both Kenya and Nigeria lacked diversity when assessed by a standardized scoring system (Table 3). While many of the cereals and tubers consumed by these populations had a low content of vitamin A, zinc and iron, cassava provided the smallest quantities of these micronutrients when expressed per unit energy (Table 2). Nigerian children received more iron and zinc in their diets, probably because they consumed a more diverse group of cereals, most of which contained more zinc and iron than cassava. Cassava has the reputation of being a staple food of individuals living with food insecurity. In this study, cassava consumption correlated with inadequate micronutrient intake, this is certainly a consequence of its low micronutrient content, but also may be determined by factors such as socio-economic status, which were not included in the regression modeling.

In Kenya, the dietary cost analyses indicated a 4.6-fold increase in spending (relative to the cost of simply meeting macronutrient requirements) is needed to provide adequate amounts of zinc, iron and vitamin A. In Nigeria, only a 1.2fold increase in spending (relative to the cost of simply 
meeting macronutrient requirements) is needed to provide adequate amounts of zinc, iron and vitamin A. Due to the high cost of these micronutrient-rich foods, it may well be more difficult for rural Kenyans to choose to increase the micronutrient content of their diet than Nigerians.

The proportions of children with inadequate micronutrient intakes were quite high in both populations surveyed. Inadequate dietary intake of a micronutrient does not correspond to clinical nutrient deficiency, although it does correlate with this health parameter. Assessment of clinical nutrient deficiency includes the biochemical measurement of a biological sample from the child. For zinc, iron and vitamin $\mathrm{A}$, methods of biochemical assessment have limitations that prevent their widespread use [25-27]. Unfortunately, published rates of nutrient deficiency are also very high in Nigerian and Kenyan children. In a sample of 555 rural Kenyan children, $52 \%$ of children were iron deficient, $66 \%$ were zinc deficient, and $89 \%$ were vitamin A deficient [28]. In Nigeria, one survey found that $37 \%$ of pre-school aged children were iron deficient [29], and $26-75 \%$ of pre-school aged children were vitamin A deficient $[30,31]$.

Supplementation/fortification research to reduce micronutrient deficiency has been very successful. A meta-analyses of eight studies of vitamin A supplementation found that supplementation resulted in a $23 \%$ reduction in child mortality [32]. Zinc supplementation reduced the incidence and duration of diarrhea by $15-24 \%$, as well as reducing the rate of lower respiratory infection and death [33]. The use of iron fortified maize flour resulted in an $89 \%$ reduction in iron-deficiency anemia in children [34].

Translating the research about supplementation into effective public health programs has been challenging. The most successful program is UNICEF's biannual administration of vitamin A capsules [22]. This program has a $68 \%$ global coverage and saves hundreds of thousands of lives annually. However, supplementation has the lowest coverage among rural communities in Africa, where children are most likely to die as a result of vitamin A deficiency, and requires billions of dollars to sustain. There have not been widespread public health programs that have increased zinc and iron intake.

Given that public health micronutrient supplementation programs are expensive and leave gaps in the coverage of vulnerable populations, alternatives which incorporate more micronutrients into staple crops are being explored. Staple crops have been bred to increase essential mineral and $\beta$ carotene content [34]. However, the degree of nutrient enhancement that can be achieved by breeding is typically less than 2-fold for minerals and 10-fold for carotenoids. Yellow cassava roots, for example, have a 10-fold increase in $\beta$-carotene, but no varieties of cassava have been identified with substantial zinc or iron content.
Another strategy to improve micronutrient intake is through biotechnology, genetic modification of staple crops [35]. A novel cassava biotechnology project has developed cassavas with increased vitamin A, zinc and iron content in model cultivars that exceed the ranges found in natural germplasm [36]. We speculate that if $\beta$-carotene content of cassava is increased 20 -fold or if zinc and iron content are increased 4-fold, adoption of these cassavas by farmers would have the potential to significantly increase micronutrient dietary intake. Use of biotechnology would not require the adoption of new varieties of staple foods if these traits could be introduced in crop varieties that farmers already prefer.

\section{Conclusion}

Cassava consumers are at high risk for inadequate vitamin A, zinc and iron intake. Efforts to ameliorate this risk via supplementation programs and the introduction of micronutrient-fortified crops should be directed toward cassava consuming communities.

Acknowledgements The study was funded by the Bill and Melinda Gates Foundation. The funding agency played no role in the study design, data analyses or the conclusions drawn from the data. We thank Violet Gathara and Vincent Osidiana for the work in the field collecting data and samples.

Open Access This article is distributed under the terms of the Creative Commons Attribution Noncommercial License which permits any noncommercial use, distribution, and reproduction in any medium, provided the original author(s) and source are credited.

\section{References}

1. Black RE, Allen LH, Bhutta ZA et al (2008) Maternal and child undernutrition: global and regional exposures and health consequences. Lancet 371:243-260

2. Tan Z, Ma G, Lin L et al (2002) Prevalence of subclinical vitamin A deficiency and its affecting factors in 8,669 childrens of China. Zhonghua Yu Fang Yi Xue Za Zhi 36(3):161-163

3. Sandstrom B, Sandberg AS (1992) Inhibitory effects of isolated inositol phosphates on zinc absorption in humans. J Trace Elem Electrolytes Health Dis 6:99-103

4. Preventing Iron Deficiency in Women and Children: Background and Consensus on Key Technical Issues and Resources for Advocacy, Planning and Implementing National Programmes (1998). UNICEF/ UNO/WHO/MI Technical Workshop, New York, NY

5. FAOstat data available at http://faostat.fao.org/site/567/Desktop Default.aspx?PageID $=567$ \#ancor

6. Nweke F, Haggablade S, Zulu B (2004) Recent growth in African cassava, building on success in African agriculture. Focus 12, Brief 3. International Food Policy Research Institute (IFPRI) 2004

7. Nweke FI (1994) Cassava distribution in Africa. COSCA Working Paper No. 12. Collaborative study of cassava in Africa. IITA, Ibadan, Nigeria 
8. Maziya-Dixon B, Kling JG, Menkir A, Dixon A (2000) Genetic variation in total carotene, iron and zinc contents of maize and cassava genotypes. Food Nutr Bull 21:419-422

9. Maziya-Dixon B, Nokoe S, Manyong V, Harris E, Akinyele IO, Oguntona EB, Sanusi RA (2006) Report on survey design and operation: Nigeria Food Consumption and Nutrition Survey 2001-2003. International Institute of Tropical Agriculture, Ibadan

10. Maziya-Dixon BB, Akinyele IO, Sanusi RA, Oguntona TE, Nokoe SK, Harris EW (2006) Vitamin A deficiency is prevalent in children less than 5 y of age in Nigeria. J Nutr 136:2255-2261

11. Okali D, Okpara E, Olawoye J (2001) Rural-urban interactions and livelihood strategies series. The case of Abia and its region, southern Nigeria. Working paper 4. International Institute for Environmental and Development. London, UK

12. Karvetti RL, Knuts LR (1985) Validity of the 24-hour dietary recall. J Am Diet Assoc 85:1437-1442

13. Gibson RS, Ferguson EL (2008) An interactive 24-hour recall for assessing the adequacy of iron and zinc intakes in developing countries. Harvest Plus technical monograph series. Harvest Plus, UNU

14. Lukmanji Z, Hertzman E, Mlingi N, Assey V, Ndossi G, Fawzi W (2008) Tanzania Food Composition Tables. Muhumbili School of Health and Allied Sciences, Tanzania, available at http://www.hsph. harvard.edu/nutritionsource/files/tanzania-food-composition-tables.pdf

15. The World Food Dietary Assessment System (NFOOD) (1997): WFOOD, Version 2.0 Berkeley, CA. University of California, Berkeley. [computer program]

16. Institute of Medicine (2001) Dietary reference intakes for vitamin $\mathrm{A}$, vitamin $\mathrm{K}$, arsenic, boron, chromium, copper, iodine, iron, manganese, molybdenum, nickel, silicon, vanadium and zinc. National Academies Press, Washington

17. WHO Anthro 2005 Beta. Available at http://www.who.int/child growth/software/en/

18. Swindale A, Bilinsky P (2006) Household dietary diversity score (HHDS) for measurement of household food access: indicator guide. Food and Nutrition Technical Assistance Project, Washington

19. Ruel M (2002) Is dietary diversity an indicator of food security of dietary quality? A review of measurement issues and research needs. IFPRI FCND Discussion Paper 140, Washington

20. Briend A, Darmon N, Ferguson E, Erhardt JG (2003) Linear programming: a mathematical tool for analyzing and optimizing children's diets during the complementary feeding period. J Pediatr Gastroenterol Nutr 36:12-22

21. Thompson FE, Byers T (1994) Dietary assessment resource manual. J Nutr 124:2245-2317
22. UNICEF (2007) Vitamin A supplementation: A decade of progress. UNICEF, New York

23. http://www.unicef.org/infobycountry/nigeria statistics.html

24. McCall D, McGartland C, Woodside JV, Young IS (2005) Micronutrients: dietary intake v. supplement use. Proc Nutr Soc 64:543-553

25. World Health Organization (1996) Indicators for assessing vitamin A deficiency and their application in monitoring and evaluating intervention programs. WHO, Geneva

26. International Zinc Consultative Group (2004) Assessment of the risk of zinc deficiency in populations. Food Nutr Bull 25:S130 S162

27. Cook JD, Baynes RD, Skikne BS (1992) Iron deficiency and the measurement of iron status. Nutr Res Rev 5:189-202

28. Siekmann JH, Allen LH, Bwibo NO, Demment MW, Murphy SP, Neumann CG (2003) Kenyan school children have multiple micronutrient deficiencies, but increased plasma vitamin B-12 is the only detectable micronutrient response to meat or milk supplementation. J Nutr 133:3972S-3980S

29. Jeremiah ZA, Buseri FI, Fiekumo I, Uko EK, Emmanuel K (2007) Iron deficiency anaemia and evaluation of the utility of iron deficiency indicators among healthy Nigerian children. Hematol 12:249-253

30. Oso OO, Abiodun PO, Omotade OO, Oyewole D (2003) Vitamin A status and nutritional intake of carotenoids of preschool children in Ijaye Orile community in Nigeria. J Trop Pediatr 49:42-47

31. Uzoechina ON, Okoro BA (1994) Serum vitamin A levels of preschool children in a Nigerian rural community. Ann Trop Paediatr 14:157-161

32. Beaton GH, Martorell R, Aronson KJ, Edmonston B, McCabe G, Ross AC et al (1993) Effectiveness of Vitamin A Supplementation in the Control of Young Child Morbidity and Mortality in Developing Countries, ACC/SCN State-of-the-Art Series, Nutrition Policy Paper No. 13, Geneva

33. Bhutta ZA, Ahmed Z, Black RE, Cousens S, Dewey K, Giugliani E, Haider BA, Kirkwood B, Morris SS, Sachdev HPS, Shekar M (2008) What works? Interventions for maternal and child undernutrition and survival. Lancet 371:417-440

34. Pfeiffer W, McClafferty B (2007) Biofortification: Breeding micronutrient-dense crops. In: Kang MPP, Priyadarshan PM (eds) Breeding Major Food Staples. Blackwell Publishing, Ames, pp 61-91

35. Nestel P, Bouis HE, Meenakshi JV, Pfeiffer W (2006) Biofortification of staple food crops. J Nutr 126:1064-1067

36. Sautter C, Poletti S, Zhnag P, Gruissem W (2006) Biofortification of essential nutritional compounds and trace elements in rice and cassava. Proc Nutr Soc 65:153-159 